\title{
Scholarly Activities of the Most Productive CLS Faculty and Schools in the U.S.A.
}

\author{
KATHY V WALLER, KAREN R KARNI
}

OBJECTIVES: To assess the research and scholarship of the most productive clinical laboratory science faculty and schools in the United States.

DESIGN: In 2008 a national study involving 106 college and university CLS programs was conducted to determine which faculty members were most productive in research activities. A questionnaire was sent electronically to all faculty $(n=448)$ of 106 NAACLS accredited programs. Data from 275 respondents (61\%), from 93 programs (89\%) were analyzed.

SETTING: The study took place at The Ohio State University with collaboration from the University of Minnesota.

PARTICIPANTS: Clinical laboratory science faculty within a four-year university or college sponsoring a NAACLS-accredited CLS program, were invited to participate.

MAIN OUTCOME MEASURES: To quantitate faculty scholarly productivity by point assessment, to assess the top $10 \%$ of faculty based on funding, publications, abstracts, presentations, books and chapters, and to identify the 15 highest ranking institutions in terms of their collective faculty research contributions.

CONCLUSIONS: The top $10 \%$ of clinical laboratory science faculty $(\mathrm{n}=28)$ are performing almost $50 \%$ of scholarship in the profession, with major contributions in funding garnered and international presentations. These individuals also generally hold a doctorate, are full professors and tenured. Among the 15 highest ranked colleges and universities with CLS programs, and by cumulative faculty contributions, most are classified as research institutions.
ABBREVIATIONS: CLS = clinical laboratory science

INDEX TERMS: clinical laboratory science faculty, research productivity, scholarship

Clin Lab Sci 2010;23(3):175

Kathy V. Waller Ph.D., CLS (NCA), The Ohio State University, Columbus, OH 43210

Karen R. Karni, Ph.D., CLS (NCA), Professor Emeritus, University of Minnesota, Sciences, Minneapolis, MN 55455

Address for Correspondence: Kathy V. Waller Ph.D., CLS (NCA), Associate Professor, The Ohio State University, 535 Atwell Hall, 453 W. 10 th Avenue, Columbus, OH 43210, Waller.1@osu.edu, 614-2927303

\section{INTRODUCTION}

In many colleges and universities in the United States, faculty members are expected to engage in scholarship (research and its sequelae - publications, abstracts, presentations, books, chapters and grants awarded). In addition, educational institutions and their individual programs are often rated and ranked by the research output of their faculty.

Faculty members who engage in research and are productive in that research are often rewarded through tenure, promotion, and salary increases. Those who are viewed as being less productive may lose their positions, not be promoted, or suffer from limited salary increases. Thus, research and productivity are important for individual faculty members' success as well as that of their employing institutions. 


\section{RESEARCH AND REPORTS}

In 1996 we conducted a survey of Clinical Laboratory Science (CLS) faculty research activities, in which we evaluated and quantitated the output of individual faculty members as well as of colleges and universities within the profession. ${ }^{1}$ This article provides an update on what our most productive faculty members are accomplishing in research, as well as which schools can be designated as highest in ranking in their faculty members' cumulative scholarly activities.

\section{MATERIALS AND METHODS}

A survey questionnaire was sent electronically via SurveyMonkey ${ }^{\odot}$ to all faculty in National Accrediting Agency for Clinical Laboratory Sciences (NAACLS) accredited college and university based baccalaureate level CLS programs $(n=106)$ in May 2008. The instrument sought information on demographics and faculty involvement in research activities to include time spent in research, numbers of publications, presentations, and grants awarded. Responses were received from 275 of 448 (61\%) CLS individuals. Details of the methodology can be seen in a recent article. $^{1}$

We assigned a numerical value to quantitate various aspects of scholarship as was done in the earlier 1996 study. ${ }^{2}$ A research score was calculated for each respondent and from these data, the top 10 percent $(\mathrm{n}=$ 28) of CLS researchers was identified. Finally, the authors identified the 15 most productive institutions according to all responding faculty members' scholarship.

\section{RESULTS}

The point determination for scholarly activities is shown in Table 1 and was adapted slightly from the 1996 study. $^{2}$ Point values increased with increasing value of the activity, and as often related to promotion and tenure decisions. For example, grant monies awarded over $\$ 1$ million dollars were valued at 20 points compared to 3 points for monies awarded for less than $\$ 10,000$. An international research presentation, or refereed research publication, was each awarded 3 points, while a refereed abstract or chapter in a book received 1 point. Total points were calculated to quantitate individual faculty members as well as overall school research productivity.
Table 1. Point Determinations for Research Activities

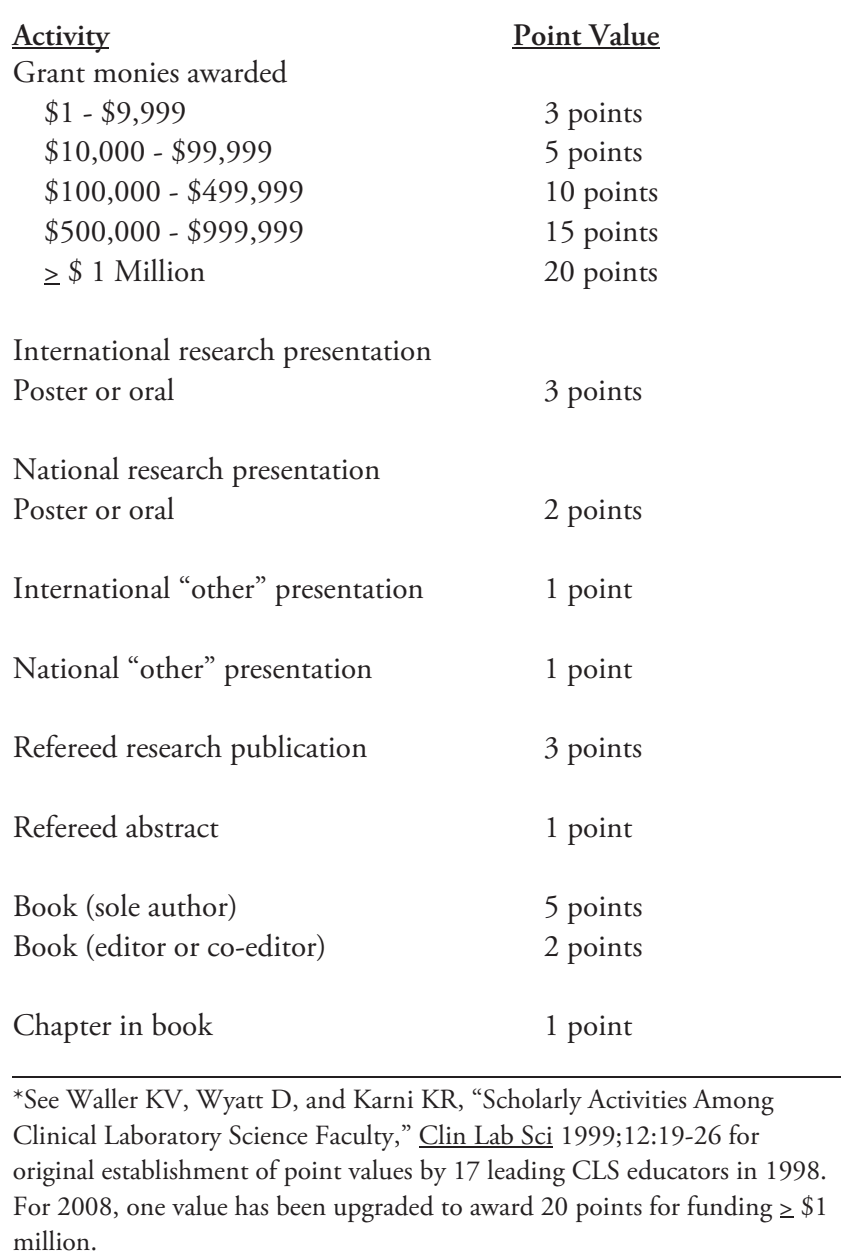

Demographic information of the top $10 \%$ of CLS faculty contributing to scholarly activities is shown in Table 2. The majority had earned a doctorate (93\%); held the academic rank of professor (54\%); and were tenured $(75 \%)$.

Figure 1 depicts the percentages of scholarly activities performed by the top $10 \%$ of CLS faculty in which individual faculty members' scholarly activities were itemized and totaled. Here, 28 faculty members were awarded both two-thirds of all funding and presented internationally. They also had $47 \%$ and $46 \%$ of research publications and refereed abstracts, but relatively low percentages of books and chapters $(22 \%$ and $29 \%$ ). 


\section{RESEARCH AND REPORTS}

Based upon all faculty point assessments, the most productive 15 CLS programs in the United States with faculty performing research and scholarly activities are listed in Table 3. (These universities are listed alphabetically, and not in rank order).

Table 2. Demographics of the Top $10 \%$ of CLS Faculty Contributing to Scholarly Activities

\begin{tabular}{lcc}
\hline Highest Level of Education & Frequency & $(\%)$ \\
Masters & 2 & 7 \\
Doctorate & 26 & 93 \\
& & \\
Academic Rank & 5 & 18 \\
$\quad$ Assistant Professor & 8 & 29 \\
Associate Professor & 15 & 54 \\
$\quad$ Professor & & \\
& & \\
Tenure Status & 21 & 75 \\
Tenured & 5 & 18 \\
Tenure Track & 2 & 7 \\
Tenure does not apply & & \\
& & \\
Type of Employing Institution & 14 & 50 \\
4-year major research university & 12 & 43 \\
4-year college/university & 2 & 7 \\
Other & & \\
\hline
\end{tabular}

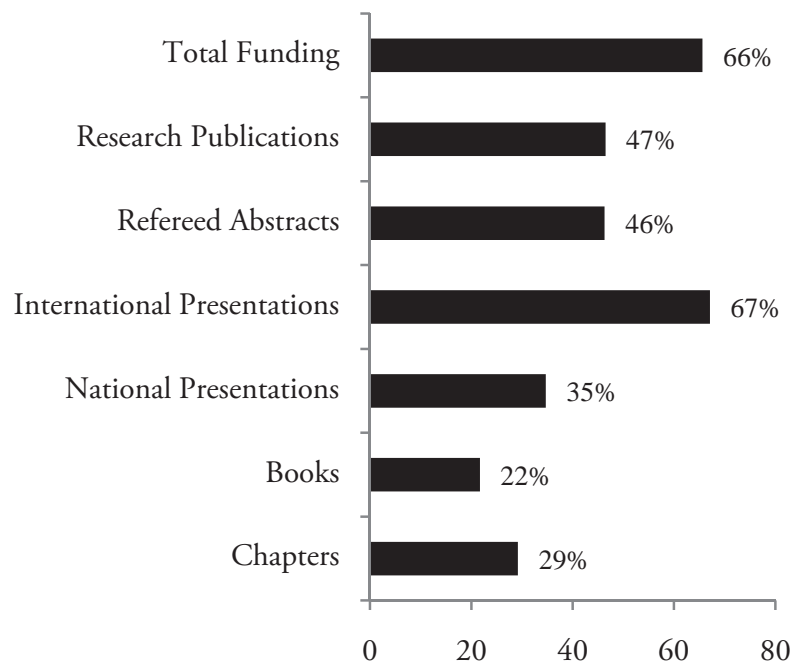

Figure 1. The Top $10 \% *$ of CLS Faculty Contribute These Percentages of Scholarly Activities

${ }^{*} \mathrm{n}=28$.

\section{DISCUSSION}

As we stated in $1998,{ }^{3}$
An individual within a 'recognized profession' participates in, and adds to the profession through, the competent practice of that profession, education of new members to the profession, and contributing to the body of knowledge of the profession. Research and scholarly activities are crucial components to validating and advancing the profession.

Table 3. Top 15 CLS Programs in the United States by Cumulative Faculty Research Productivity

Long Island University at CW Post

Louisiana State University

Medical College of Georgia*

Saint Louis University

SUNY at Buffalo*

SUNY at Stony Brook

The Ohio State University*

University of Kentucky*

University of Maryland

University of Minnesota*

University of North Carolina*

University of Texas at Galveston*

University of Texas at San Antonio*

University of Wisconsin - Madison*

University of Wisconsin - Milwaukee*

Rankings include all CLS faculty responding from each institution.

*Ten of the original 15 programs, ranked in 1996, remained among the top 15 programs in 2008.

This study represents a two decade long investigation of CLS faculty research actitites. ${ }^{4,5,6}$ It supports our 1998 findings that some CLS faculty are highly productive in research, and are similar to other studies. In 1979, for example, Krumland reported that in medicine, $10 \%$ of the faculty produced $50 \%$ of its publications. ${ }^{7}$

More recently, Webber and Lee (2009) were cited in The Chronicle of Higher Education for their work that stated, among their findings, that research productivity was enhanced by:

- Kind of school in which they were employed.

- Professors at doctoral institutions reported more refereed journal articles, book reviews and presentations than did professors at master's and 


\section{RESEARCH AND REPORTS}

baccalaureate institutions, where teaching is more likely to take up a faculty member's time.

- Discipline in which they were employed. "Faculty members in the physical and life sciences had 46 percent more refereed articles than did professors in the arts and humanities. .."

- Parenthood. “. . . being the parent of dependent children had a positive effect on research productivity."

Our findings have, first, provided quantitative point values for individual faculty members' research activities and productivity. Other investigators of faculty research may find them useful in their own studies of scholarship.

Next, the top $10 \%$ of CLS faculty have produced almost $50 \%$ of scholarly activities, much like the Krumland studies. The two findings are not unexpected. Seasoned researchers are most apt to win external funding and to present internationally, because of their previous track records and reputations within their professional communities.

Again, our studies are similar to those of Webber and Lee in the first two conclusions regarding kind of school and discipline in which one is employed. While this investigation did not look at personal factors, e.g. dependent children of faculty, it fosters further research that should be done regarding the personal status of faculty.

The relatively small percentage of the top $10 \%$ of faculty who author books and chapters is interesting. Perhaps books and chapters are not rewarded in the same ways that research publications, presentations and grants awarded are viewed. The fact that the 17 CLS "experts" earlier rated them relatively low also suggests they are not as valuable a scholarship indicator as others. Thus, research-oriented faculty may not engage in these activities, because they are not seen as important enough to their own scholarship output. Correspondingly, books and chapters reflect a "state of the art" of a discipline as previously published. They do not present new knowledge (such as refereed journal articles) and thus represent secondary presentations.
The cumulative research activities of all responding faculty members give rise to the most productive programs in the United States. Note: these 15 institutions represent the point values for all faculty responding, not just the 28 most productive members. Here there are ten returning institutions from the original 15 highest ranked and as reported in $1999 .^{2}$ Most are research institutions. Nevertheless, and as can be seen in Table 2 and from our report in Clinical Laboratory Science, ${ }^{1}$ there is no statistical difference between all faculty from research institutions or fouryear colleges. These findings suggest that while individual faculty performing research can be found in any institution, overall, research universities hold the greater numbers of productive faculty.

Finally, faculty in clinical laboratory sciences may be similar to those in other colleges and universities. Some faculty members are very productive, like the 28 persons represented in this paper. Some institutions also support highly the research activities of their faculty. It behooves us to strengthen the research efforts of all faculty members to validate and strengthen the practice of laboratory science and to contribute new knowledge to the field. Moreover, promotion, tenure and salary decisions for individual faculty members may be heavily based on research. ${ }^{1}$

\section{RECOMMENDATIONS}

As first recommended in $1988^{4}$ and repeated in $1998^{3}$, we offer these recommendations to faculty and administrators who wish to increase the scholarship of individuals and that of their programs and schools:

- Allocate teaching loads according to interest and skill, i.e., programs may assign more of the teaching to excellent teachers, and more research to excellent researchers, thereby increasing productivity in both arenas.

- Employ faculty who are interested in both research and teaching.

- Employ individuals with demonstrated research skills, or the potential to engage in scholarly activities.

- Establish collaborations with other researchers.

- Participate in research conferences. 


\section{RESEARCH AND REPORTS}

- Encourage graduate assistants to become involved actively in research projects.

- Develop research skills for students at the undergraduate as well as the graduate level.

- Work together as a profession to identify and generate funding sources.

Two decades later, we offer additional and expanded suggestions, based on this research, together with experience, including observation:

- For new junior faculty - determine early in your academic career what are the expectations and rewards of your program and school in research, teaching and service.

- For those who teach, primarily - such faculty as well as administrators should value instructors' accomplishments by disseminating the why and how of why they have been successful teachers. In many schools, teaching and mentoring and success in creative content as well as methods and delivery of instructional materials are rewarded similarly to traditional research. ${ }^{9}$

- Pursue funding sources - local, regional and national - that provide monies for research. While such sources may not mesh exactly with a faculty member's primary research interests, one can gear a proposal to the goals of the funding organization.

- For established researchers - involve yourselves in a strong mentoring role with junior faculty.

- For young researchers - "hitch your wagon to a star." Introduce yourself and your expertise (both actual and potential) to someone who is an established researcher. This individual may find your ideas and experiences to be intriguing to his/her own interests, and invite you to participate in that research.

- How is nationally funded research garnered? Much is awarded to those engaged in collaborative research. Again, collaboration is essential; find colleagues with whom you can work in a meaningful way.

- Be a team player. Promotion and tenure decisions can be quixotic. But, those faculty members who are engaged with one another, support others, and share resources and information are often successful in the review and tenure/promotion process, not only because of their scholarship, but also because of the perception that they are team players, essential to the program and school.

These activities will enhance the status and reputations of individual faculty members within and outside their own schools. They will also strengthen their institution's standings, especially when programs and schools are compared to, and ranked with, one another.

\section{REFERENCES}

1. Waller KV, Clutter JE, Karni KR. Research and scholarship of clinical laboratory science faculty members. Clin Lab Sci 2010; 23(3);Suppl:3-32-8.

2. Waller KV, Wyatt D, Karni KR. Scholarly activities among clinical laboratory science faculty. Clin Lab Sci 1999;12:19-27.

3. Waller KV, Wyatt D, Karni KR. Research productivity and activities of clinical laboratory science faculty: a follow-up study. J Allied Health 1998;27:142-9.

4. Flanigan KS, Ballinger PW, Grant $\mathrm{HK}$ et al. Research productivity profile of allied health faculty. J Allied Health 1988; 17:87-100.

5. Waller KV, Jordan L, Gierhart J et al. Research skills and the research environment: a needs assessment of allied health faculty. J Allied Health 1988;17:101-13.

6. Waller KV, Schiller MR, Snyder JR. A profile of medical technology educators' scholarly productivity and research environment. Lab Med 1988;19:655-60.

7. Krumland RB, Will EE, Gorry GA. Scientific publications of a medical school faculty. J Med Educ 1979;54:876-84.

8. June AW (reports). Personal and professional factors affect researchers' productivity, study finds. Chronicle Higher Educ November 4, 2009. Available from http://chronicle.com/ article/PersonalProfessional/49051/?sid=at\&utm_source=at\&ut m_medium=en. Accessed 2010 May 25.

9. Balogun JA, Sloan PE. Emerging trends in tenure policies and practices in nursing and allied health education. J Allied Health 2006;35:134-41. 